\title{
PRODUCTION POTENTIAL PREDICTION FOR WHEAT, BARLEY AND MAIZE BASED ON SOIL CHARACTERISTICS USING ARTIFICIAL NEURAL NETWORKS IN VARAMIN REGION, IRAN
}

\author{
YAGHMAEIAN MAHABADI, N. ${ }^{*}$ - HEMMATI ROUDBARI, S. \\ Department of Soil Science, Faculty of Agricultural Sciences, University of Guilan \\ Rasht 4199613776, Iran \\ (phone: +98-13-3369-0274; fax: +98-13-33690-0281) \\ *Corresponding author \\ e-mail: yaghmaeian_na@guilan.ac.ir \\ (Received 21 $1^{\text {st }}$ Dec 2016; accepted 24 ${ }^{\text {th }}$ Mar 2017)
}

\begin{abstract}
Due to increasing demands for agricultural products and the problems to generate new data, using proper models to predict the performance of agricultural products seems necessary. The objective of this study was to assess the ability of artificial neural networks (ANN) for yield prediction of wheat, barley and maize to determine the most important soil properties for land production potential in Varamin region, Iran. In this study, potential production was calculated using the AEZ model. ANN model inputs were soil characteristics, including the percentage of calcium carbonate, coarse fragments, gypsum, clay, silt and sand, electrical conductivity, sodium absorption ratio and $\mathrm{pH}$. ANN model output was production potential. Mean absolute error, root means square error and coefficient of determination criteria were used to evaluate the performance of the ANN. The obtained results showed that the ANN models with two hidden layers provided the most accurate prediction of production potential. Mean land production potentials for wheat, barley and maize, using ANN models were predicted respectively, as 7417.73, 6810.41 and $8922.48 \mathrm{~kg} / \mathrm{ha}$. Sensitivity analysis of models showed that wheat production potential has the most dependence on sodium absorption ratio and clay percent. Sand and coarse fragments rates were the most important parameters for predicting the barley production potential. The sodium absorption ratio and electrical conductivity were determined as the relevant and effective soil properties on maize production potential. Also, the optimum model for maize production potential prediction has less accuracy than wheat and barley. The reason of this may be differences in the environmental compatibility of various products to adverse conditions.
\end{abstract}

Keywords: FAO method, sensitivity analysis, land production potential, gross biomass production, climatic and plant parameters

\section{Introduction}

Crop yield prediction has an important role in agricultural policies such as specification of the crop price. Nowadays, using suitable models to predict the performance of agricultural products is vital, since demands for agricultural products are increasing and water and land resources are limited. Crop yield is a function of several plant agents, climatic conditions, and soil and water management (Qian et al., 2009). Therefore, the calculation of crop yield and its related indicators follow up the complex nonlinear relationships that are modeled difficulty.

In recent years, crop growth models have become increasingly important as major components of agriculture related decision support systems. Crop growth and yield models are based on a combination of soil, crop and climatic variables. Crop models and decision tools are increasingly used in the agricultural field to improve production efficiency. The combination of advance technology and agriculture to improve the 
production of crop yield is becoming more interesting recently. Due to the rapid development of new higher technology, crop models and predictive tools might be expected to become a crucial element of precision agriculture (Shearer et al., 2000).

Land production potential (LPP) estimation is considered as a prerequisite for land use planning. LPP is determined based on land characteristics for specific land use for increment of production per surface area unit. In this regard, first, radiation thermal production potential (RTPP) is calculated, using different models such as FAO model. This potential is a genetical one which is not affected by water, soil and management limitations. If soil limitations are exerted in the radiation thermal production potential, LPP is resulted.

Some adaptive and non-parametric models have been recently introduced in environmental science for predictive purposes. ANN models are a powerful empirical modeling approach and yet relatively simple compared with mechanistic models. (Bishop, 1995), the method is gaining popularity for research areas where there is little or incomplete understanding of the problem to be solved, but where training data are available. The ANN can be used to develop empirically based agronomic models. The ANN structure is based on the human brain's biological neural processes. Interrelationships of correlated variables that symbolically represent the interconnected processing neurons or nodes of the human brain are used to develop models. ANN models find relationships by observing a large number of input and output examples to develop a formula that can be used for predictions (Pachepsky et al., 1996).

Safa et al. (2015) showed that the ANN model can predict wheat production based on farm conditions (wheat area and irrigation frequency), machinery condition and farm inputs ( $\mathrm{N}$ and fungicides consumption) in Canterbury, New Zealand, with an error margin of $\pm 9 \%$. Drummond et al. (2003) evaluated the predictive ability of representative linear, nonlinear, and neural network techniques on a multiple site-year data set of grain yield and site and soil characteristics. The results showed that significant over fitting had occurred and indicated that a much larger number of climatologically unique site-years would be required in this type of analysis. Kaul et al. (2005) reported that ANN models consistently produced more accurate yield predictions than regression models for corn and soybean yield prediction under typical Maryland climatic conditions. Norouzi et al. (2010) predicted the biomass, grain yield, and grain protein in wheat grown in hilly regions using an ANN model under rainfed conditions in the semiarid and hilly regions of western Iran. The results indicated that the ANN models could explain $89-95 \%$ of the total variability in wheat biomass, grain yield, and grain protein content. Bagheri et al. (2012) determined the least important computer input parameters which affecting the silage maize yield using ANN. The results showed that adding the solar radiation and average relative humidity to the input parameter cause reduction in MSE and increasing the accuracy of the model in the process network training. Kitchen et al. (2003) and Safa et al. (2003) suggested that the feed forward back propagation neural network is the most commonly used neural network, which can approximate any function with arbitrary precision. The objective of this study was to assess the ability of artificial neural networks (ANN) for wheat, barley and maize production potential prediction and determination of the most important soil properties affecting land production potential in Varamin area, Tehran province, Iran. 


\section{Materials and methods}

\section{Study area and data compilation}

The study area with an approximate area of 2000 hectares is located between latitude $35^{\circ} 20^{\prime}$ and $35^{\circ} 24^{\prime} \mathrm{N}$ and longitude $54^{\circ} 38^{\prime}$ and $54^{\circ} 42^{\prime} \mathrm{E}$ in the Varamin area, Tehran province, Iran. The area has a mean annual rainfall of $170 \mathrm{~mm}$ and mean annual temperature of $17.4^{\circ} \mathrm{C}$ with a mean altitude of $972 \mathrm{~m}$ a.s.l. The ground water table depth is more than $10 \mathrm{~m}$. Based on U.S. Soil Taxonomy (Soil Survey Staff, 2014), the soil moisture and temperature regimes of the area are aridic and thermic, respectively.

Some of the plant characteristics such as leaf area index and harvest index were measured in the laboratory. The maximum leaf photosynthesis rate was estimated from the graph according to the crop group (Sys et al., 1991). Required climatic data for land suitability evaluation were obtained from Varamin Synoptic Meteorological Station for a 20 years period (1994-2014).

In this research based on semi-detailed soil survey, a regular grid sampling method was designed; consequently 50 soil profiles with $600 \mathrm{~m}$ intervals were investigated. Soil samples were collected from different horizons of the profiles. Prepared samples were subsequently analyzed for required soil properties in land suitability evaluation (Sys et al., 1993) using standard methods (Soil Survey Staff, 1996). For determining the mean values of the soil physical and chemical properties for the upper $1 \mathrm{~m}$ of the soil depth, the profile was subdivided into 4 equal sections and weighting factors of 1.75, 1.25, 0.75 , and 0.25 were attributed for each section, respectively (Sys et al., 1991).

The land characteristics, i.e., climatic data and soil properties, with studied plant requirement tables presented by Sys et al. (1993), were matched. Consequently, the square root formula was used to calculate the soil index (SI). Soil index reflects the soil, topography and drainage limitations for irrigated farming. The relevant equation is as follows:

$$
\mathrm{SI}=\mathrm{R}_{\min } \times \sqrt{\frac{A}{100} \times \frac{B}{100} \times \ldots}
$$

where, SI, is the specified soil index; A, B, etc., are different ratings for each soil characteristic and $\mathrm{R}_{\min }$ is the minimum rank or value (Sys et al., 1991).

To calculate the radiation-thermal production potential of wheat, barley and maize based on FAO model (Sys et al., 1991), the following were measured or calculated:

- Respiration coefficient was calculated as follows:

$$
\mathrm{Ct}=\mathrm{C} 30\left(0.044+0.0019 \mathrm{t}+0.001 \mathrm{t}^{2}\right)
$$

where, $\mathrm{Ct}$, respiration coefficient; $\mathrm{C} 30$ of 0.0108 for non-legumes and $\mathrm{t}$, mean daily temperature of the growing cycle $\left({ }^{\circ} \mathrm{C}\right)$.

- Maximum gross biomass production ratio was calculated according to:

$$
\begin{gathered}
\operatorname{bgm}=f \times \operatorname{bo}(1+0.002 y)+(1-f) \times b c(1+0.005 y) \\
y=|(P m-20) \times 5|
\end{gathered}
$$


where, bgm, maximum gross biomass production rate $\left(\mathrm{kg} \mathrm{CH}_{2} \mathrm{O} / \mathrm{ha} . \mathrm{hr}\right)$; $\mathrm{f}$, fraction of the daytime that the sky is overcast; bo, maximum gross biomass production on overcast days ( $\mathrm{kg} \mathrm{CH} \mathrm{CH}_{2} \mathrm{O}$ /ha.day); bc, maximum gross biomass production on clear days ( $\mathrm{kg} \mathrm{CH}_{2} \mathrm{O} /$ ha.day) and $\mathrm{Pm}$, maximum leaf photosynthesis rate $\left(\mathrm{kg} \mathrm{CH}_{2} \mathrm{O} / \mathrm{ha}\right.$.hr).

- Radiation-thermal production potential was calculated as follows:

$$
\mathrm{Y}=(0.36 \times \operatorname{bgm} \times \mathrm{KLAI} \times \mathrm{Hi}) /[1 / \mathrm{L} \times 0.25 \mathrm{Ct}]
$$

where, Y, radiation-thermal production potential $(\mathrm{kg} / \mathrm{ha})$; bgm, maximum gross biomass production rate ( $\mathrm{kg} \mathrm{CH}_{2} \mathrm{O} /$ ha.day); KLAI, leaf area index at maximum growth rate; $\mathrm{Hi}$, harvest index; L, growth cycle (day) and $\mathrm{Ct}$, respiration coefficient.

Finally, LPP was calculated according to:

$$
\mathrm{LPP}=\mathrm{Y} \times \mathrm{SI}
$$

where, LPP, the land production potential $(\mathrm{kg} / \mathrm{ha}) ; \mathrm{Y}$, radiation-thermal production potential (kg/ha) and SI, the soil index.

Land and soil characteristics were included topography, wetness and drainage conditions, soil texture and structure, the percentage of coarse fragments, equivalent $\mathrm{CaCO}_{3}$ percent, gypsum percent, soil depth, electrical conductivity (EC), sodium absorption ratio (SAR) and $\mathrm{pH}$. The growing period was determined based on climatic data (i.e., rainfall, temperature, relative humidity, hours of bright sunshine and wind speed) using graphical method. To calculate the evapotranspiration, CropWat software was used.

\section{Artificial neural network model development}

In this paper, the feed forward back propagation neural network as the most commonly used neural network architecture was applied. The first term, "feed forward" describes how this neural network processes and recalls patterns. "Back-propagation" is a form of supervised learning where the error rate is sent back through the network to alter the weights to improve prediction and decrease error. Supervised learning, which applies known outputs to train the ANN, is more commonly used than unsupervised learning (Wieland and Mirsche, 2008).

Since, the climatic characteristics and topographic conditions were entirely equal within the study area; they were not considered as the ANN inputs. ANNs can identify and learn correlated patterns between input data sets and corresponding target values through training. The trained network is then tested with a separate data set with its output information omitted. Training data sets were used to develop models including field-specific: equivalent $\mathrm{CaCO}_{3}$ percent, percentage of coarse fragments, gypsum, clay silt and sand percent, EC, SAR and $\mathrm{pH}$ as inputs with associated land production potential as output. The training and testing process have been carried out for around $80 \%$ and $20 \%$ of the sample data set respectively in each of the cases under study.

Since, the sigmoid threshold function was used in the hidden layer and its output values are between 0 and 1, therefore the data sets were normalized using the following equation (Montazar et al., 2009):

$$
\mathrm{X}_{\mathrm{n}}=0.5\left(\frac{\mathrm{X}_{\mathrm{O}}-\mathrm{X}_{\text {ave }}}{\mathrm{X}_{\max }-\mathrm{X}_{\min }}\right)+0.5
$$


where $X_{n}$, the normalized data; $X_{o}$, the input data; $X_{\text {ave }}$, the average of data, $X_{\min }$ and $\mathrm{X}_{\max }$, the minimum and maximum data value, respectively.

Training neural network models was founded on the basis of trial and error. Adjustment of ANN parameters were included the number of hidden nodes and hidden layers, learning rate, training function type and training tolerance. So that, the optimum neural network architecture was obtained from changing the mentioned parameters. For each step, multiple linear regression models between the actual and predicted yields were applied. The coefficient of determination $\left(\mathrm{R}^{2}\right)$ and root mean square error (RMSE) were calculated to find the optimum neural network architecture. The different threshold functions such as logarithmic sigmoid function, linear and hyperbolic tangent functions were used to improve neural network performance. Finally, the best neural network architecture was obtained for prediction of wheat, barley and maize land production potential. The performance of developed models was evaluated using by mean absolute error (MAE), RMES and $\mathrm{R}^{2}$ (Tang et al., 1997). The ANN models were developed in MATLAB 10.1 software.

The sensitivity analysis must be conducted to detect the robustness of every ANN model because different choices of function and parameters in ANN models would influence the performance of simulation (Zhang et al., 2007). In this research, sensitivity analysis was done using Statfsoft method (StatSoft, 2004). The sensitivity coefficient values of the inputs obtained by dividing the total network error in the absence of one variable on the total network error in the presence of all the variables. According to this, if the sensitivity coefficient value of variable is more than 1 , the variable has a great impression in the variability of the components of yield (Norouzi, 2010).

\section{Results and discussion}

Required plant and climatic characteristics for calculation of wheat, barley and maize radiation-thermal production potential were presented in Table 1. Regarding to FAO model, the radiation-thermal production potential of wheat, barley and maize were obtained 7417.73, 6810.41, and 8922.48 (kg/ha), respectively. Of course, it is impossible to achieve such production because anyway, there are soil and management limiting factors in irrigated farming. In other words, the difference between the LPP and farmer yield is due to these limitations. Table 2 shows summary statistics of the studied soil attributes used in the training and testing process. The studied soils have a wide range of EC, SAR and particle size distribution (Table 2).

\section{The designed ANN models}

In this study, one and two hidden layer structure and one to 14 numbers of neurons in hidden layers was applied in network training. Eight optimized ANN models for wheat and maize and seven optimized models for barley production potential predication were achieved. Table 3 shows the characteristics of ANN models. The efficiency of models for estimation of LPP was compared with $\mathrm{R}^{2}$, RMSE and MAE statistics (Table 4). 
Table 1. Required crop and climatic parameters for calculation of radiation-thermal production potential for wheat, barley and maize

\begin{tabular}{|c|c|c|c|}
\hline Parameters & Wheat & Barley & Maize \\
\hline Crop group & C3, Group 1 & C3, Group 1 & C4, Group IV \\
\hline Mean temperature of the growing cycle $\left({ }^{\circ} \mathrm{C}\right)$ & 22.0 & 20.13 & 31.53 \\
\hline Maximum leaf photosynthesis rate $\left(\mathrm{kg} \mathrm{CH}_{2} \mathrm{O} / \mathrm{ha} \cdot \mathrm{hr}\right)$ & 20 & 20 & 65 \\
\hline Leaf area index $\left(\mathrm{m}^{2} \cdot \mathrm{m}^{-2}\right)$ & 4.5 & 4.5 & 4.0 \\
\hline Harvest index & 0.45 & 0.40 & 0.35 \\
\hline Mean of bo $\left(\mathrm{kg} \mathrm{CH}_{2} \mathrm{O} / \mathrm{ha} \cdot \mathrm{hr}\right)$ & 204.24 & 192.01 & 243.83 \\
\hline Mean of bc $\left(\mathrm{kg} \mathrm{CH}_{2} \mathrm{O} / \mathrm{ha} \cdot \mathrm{hr}\right)$ & 394.44 & 373.90 & 461.17 \\
\hline $\mathrm{f}$ & 0.25 & 0.27 & 0.13 \\
\hline $\mathrm{Ct}$ & $5.2 \times 10^{-3}$ & $4.4 \times 10^{-3}$ & $1.1 \times 10^{-2}$ \\
\hline Radiation-thermal production potential $(\mathrm{kg} / \mathrm{ha})$ & 7417.73 & 6810.41 & 8922.48 \\
\hline
\end{tabular}

Table 2. Summary statistics of data sets in testing and training steps neural networks

\begin{tabular}{|c|c|c|c|c|c|c|c|c|}
\hline \multirow[t]{2}{*}{ Soil characteristics } & \multicolumn{4}{|c|}{ Training step } & \multicolumn{4}{|c|}{ Testing step } \\
\hline & Minimum & Maximum & Mean & $\mathrm{Cv}^{\mathrm{a}}(\%)$ & Minimum & Maximum & Mean & $\mathrm{Cv}(\%)$ \\
\hline $\mathrm{EC}(\mathrm{dS} / \mathrm{m})$ & 0.4 & 14.8 & 4.1 & 90.5 & 1.2 & 14.3 & 4.5 & 93.5 \\
\hline $\mathrm{pH}$ & 7.5 & 8.7 & 8.2 & 3.8 & 8.2 & 8.8 & 8.2 & 4.1 \\
\hline SAR & 0.2 & 35.2 & 9.2 & 95.5 & 3.7 & 26.4 & 8.3 & 96.6 \\
\hline $\mathrm{CaCO}_{3}(\%)$ & 5.7 & 14.8 & 9.1 & 2.3 & 6.8 & 11.7 & 8.3 & 2.7 \\
\hline Coarse fragments $(\%)$ & 0.0 & 49.0 & 23.6 & 69.3 & 26.2 & 42.8 & 24.5 & 61.5 \\
\hline Gypsum (\%) & 1.0 & 6.2 & 1.7 & 69.6 & 1.1 & 2.1 & 1.3 & 24.8 \\
\hline Clay $(\%)$ & 0.0 & 16.6 & 6.5 & 79.5 & 0.0 & 13.7 & 5.1 & 100.1 \\
\hline Silt (\%) & 5.5 & 56.6 & 18.2 & 62.8 & 9.2 & 32.4 & 16.8 & 42.8 \\
\hline Sand $(\%)$ & 30.3 & 94.5 & 75.3 & 19.9 & 88.0 & 92.5 & 78.1 & 15.2 \\
\hline
\end{tabular}

${ }^{\mathrm{a}}$ Coefficient of variation 
Table 3. Characteristics of artificial neural networks models

\begin{tabular}{|c|c|c|c|c|c|c|c|c|c|}
\hline & Model & 1 & 2 & 3 & 4 & 5 & 6 & 7 & 8 \\
\hline \multirow{3}{*}{$\begin{array}{l}\frac{n}{0} \\
\frac{0}{0} \\
\frac{Z}{4}\end{array}$} & Network type & $\mathrm{MLP}^{\mathrm{a}}$ & MLP & MLP & MLP & MLP & MLP & MLP & MLP \\
\hline & Training method & $\mathrm{BP}^{\mathrm{b}}$ & $\mathrm{BP}$ & $\mathrm{BP}$ & $\mathrm{BP}$ & $\mathrm{BP}$ & $\mathrm{BP}$ & $\mathrm{BP}$ & $\mathrm{BP}$ \\
\hline & Training process & Epochs & Epochs & Epochs & Epochs & Epochs & Epochs & Epochs & Epochs \\
\hline \multirow{5}{*}{$\begin{array}{l}\overrightarrow{\widetilde{J}} \\
\frac{\Xi}{3}\end{array}$} & Training function & bfg & br & $\operatorname{gdm}$ & $\operatorname{scg}$ & $\operatorname{gdm}$ & br & $\operatorname{scg}$ & bfg \\
\hline & No. of hidden layers & 1 & 1 & 1 & 1 & 2 & 2 & 2 & 2 \\
\hline & No. of neurons in hidden layers & 12 & 9 & 8 & 7 & $5-9$ & $6-8$ & $9-12$ & $7-9$ \\
\hline & Epochs & 16 & 16 & 16 & 16 & 16 & 16 & 16 & 16 \\
\hline & Momentum & 0.4 & 0.4 & 0.4 & 0.4 & 0.4 & 0.4 & 0.4 & 0.4 \\
\hline \multirow{5}{*}{$\frac{\vec{d}}{\bar{\Xi}}$} & Training function & $\operatorname{scg}$ & $\operatorname{scg}$ & $\mathrm{gdm}$ & bfg & gdm & $\operatorname{scg}$ & $\operatorname{scg}$ & - \\
\hline & No. of hidden layers & 1 & 1 & 1 & 1 & 2 & 2 & 2 & - \\
\hline & No. of neurons in hidden layers & 13 & 10 & 8 & 5 & $9-12$ & $8-10$ & $5-11$ & - \\
\hline & Epochs & 16 & 16 & 16 & 16 & 16 & 16 & 16 & - \\
\hline & Momentum & 0.6 & 0.6 & 0.6 & 0.6 & 0.6 & 0.6 & 0.6 & - \\
\hline \multirow{5}{*}{$\begin{array}{l}\stackrel{N}{\pi} \\
\sum\end{array}$} & Training function & bfg & br & $\operatorname{scg}$ & $\operatorname{scg}$ & $\operatorname{scg}$ & br & bfg & bfg \\
\hline & No. of hidden layers & 1 & 1 & 1 & 1 & 2 & 2 & 2 & 2 \\
\hline & No. of neurons in hidden layers & 10 & 9 & 8 & 6 & $6-8$ & $9-11$ & $7-9$ & $6-9$ \\
\hline & Epochs & 16 & 16 & 16 & 16 & 16 & 16 & 16 & 16 \\
\hline & Momentum & 0.3 & 0.3 & 0.3 & 0.3 & 0.3 & 0.3 & 0.3 & 0.3 \\
\hline
\end{tabular}

${ }^{\text {a }}$ Multi-layer perceptron

${ }^{\mathrm{b}}$ Back propagation 
Table 4. Statistical results of tested artificial neural networks models for prediction of wheat, barley and maize production potential

\begin{tabular}{|c|c|c|c|c|}
\hline \multirow{2}{*}{ రి } & \multirow[b]{2}{*}{ Model } & \multicolumn{3}{|c|}{ Testing step } \\
\hline & & $\mathbf{R}^{2}$ & RMSE & MAE \\
\hline \multirow{8}{*}{$\frac{\vec{\varpi}}{\mathbb{J}^{2}}$} & 1 & 0.698 & 0.326 & 0.249 \\
\hline & 2 & 0.743 & 0.401 & 0.344 \\
\hline & 3 & 0.690 & 0.360 & 0.299 \\
\hline & 4 & 0.723 & 0.475 & 0.366 \\
\hline & 5 & 0.703 & 0.314 & 0.189 \\
\hline & 6 & 0.682 & 0.193 & 0.251 \\
\hline & 7 & 0.780 & 0.310 & 0.245 \\
\hline & 8 & 0.686 & 0.285 & 0.074 \\
\hline \multirow{7}{*}{$\frac{\widehat{d}}{\bar{I}}$} & 1 & 0.809 & 0.105 & 0.216 \\
\hline & 2 & 0.752 & 0.092 & 0.202 \\
\hline & 3 & 0.873 & 0.559 & 0335 \\
\hline & 4 & 0.827 & 0.449 & 0344 \\
\hline & 5 & 0.738 & 0.426 & 0.036 \\
\hline & 6 & 0.863 & 0.586 & 0.125 \\
\hline & 7 & 0.892 & 0.299 & 0.235 \\
\hline \multirow{8}{*}{ 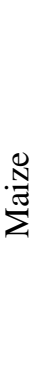 } & 1 & 0.605 & 0.221 & 0.270 \\
\hline & 2 & 0.600 & 0.542 & 0.165 \\
\hline & 3 & 0.707 & 0.499 & 0.399 \\
\hline & 4 & 0.731 & 0.470 & 0.364 \\
\hline & 5 & 0.746 & 0.426 & 0.352 \\
\hline & 6 & 0.669 & 0.301 & 0.268 \\
\hline & 7 & 0.728 & 0.653 & 0.194 \\
\hline & 8 & 0.659 & 0.635 & 0.231 \\
\hline
\end{tabular}

The ANN models were ranked based on the highest $\mathrm{R}^{2}$ and the lowest RMSE and MAE for selection the best one. Numerical values were assigned to the best and worst models ( 1 to 8 for wheat and maize and 1 to 7 for barley). Based on the sum of these values, ANN models were ranked: the models with the lowest and the highest sum of scores had the highest and lowest worthiness, respectively. Ranking of models for selection of the optimum model was presented in Table 5. The results for each crop were as follows:

\section{Wheat production potential prediction by proposed ANN model}

Model No. 7 in Table 3 as the best ANN model for estimation of wheat production potential, has 10 input layers and one output layer. The number of neurons in two hidden layers has been taken as 9 and 12. This model has the lowest sum of the scores and the highest ranking in training process (Table 5). Fig. 1 shows high correlations between calculated FAO production potential and predicted ANN production potential $\left(\mathrm{R}^{2}=0.924\right)$. High coefficient of determination reflects the ability of ANN for estimation of the wheat production potential. Also, $\mathrm{R}^{2}$ of 0.780 , RMSE of 0.310 and MAE of 0.245 in training stage confirm the efficiency of the proposed ANN model 
(Table 4). The highest and the lowest estimated wheat production potential by the optimum model were: 5013 and 749 (kg/ha), respectively (Table 6).

Table 5. Ranking of artificial neural networks for selection of optimum model

\begin{tabular}{|c|c|c|c|c|c|c|}
\hline \multirow{2}{*}{ ڤั่ } & \multirow[b]{2}{*}{ Model } & \multicolumn{3}{|c|}{ Scores } & \multirow{2}{*}{$\begin{array}{l}\text { Sum. of } \\
\text { scores }\end{array}$} & \multirow{2}{*}{$\begin{array}{c}\text { Optimum } \\
\text { model }\end{array}$} \\
\hline & & $\mathbf{R}^{2}$ & RMSE & MAE & & \\
\hline \multirow{8}{*}{ 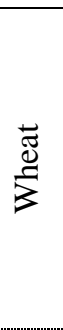 } & 1 & 5 & 5 & 4 & 14 & 7 \\
\hline & 2 & 2 & 7 & 7 & 16 & 8 \\
\hline & 3 & 6 & 6 & 6 & 18 & 5 \\
\hline & 4 & 3 & 8 & 8 & 19 & 6 \\
\hline & 5 & 4 & 4 & 2 & 10 & 1 \\
\hline & 6 & 8 & 1 & 5 & 14 & 2 \\
\hline & 7 & 1 & 3 & 3 & 7 & 3 \\
\hline & 8 & 7 & 2 & 1 & 10 & 4 \\
\hline \multirow{7}{*}{ 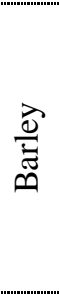 } & 1 & 5 & 2 & 4 & 11 & 7 \\
\hline & 2 & 6 & 1 & 3 & 10 & 2 \\
\hline & 3 & 2 & 6 & 6 & 14 & 1 \\
\hline & 4 & 4 & 5 & 7 & 16 & 5 \\
\hline & 5 & 7 & 4 & 1 & 12 & 6 \\
\hline & 6 & 3 & 7 & 2 & 12 & 3 \\
\hline & 7 & 1 & 3 & 5 & 9 & 4 \\
\hline \multirow{8}{*}{ 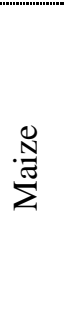 } & 1 & 7 & 1 & 5 & 13 & 5 \\
\hline & 2 & 8 & 6 & 1 & 15 & 6 \\
\hline & 3 & 4 & 5 & 8 & 17 & 1 \\
\hline & 4 & 2 & 4 & 7 & 13 & 7 \\
\hline & 5 & 1 & 3 & 6 & 10 & 4 \\
\hline & 6 & 5 & 2 & 4 & 11 & 2 \\
\hline & 7 & 3 & 8 & 2 & 13 & 8 \\
\hline & 8 & 6 & 7 & 3 & 16 & 3 \\
\hline
\end{tabular}

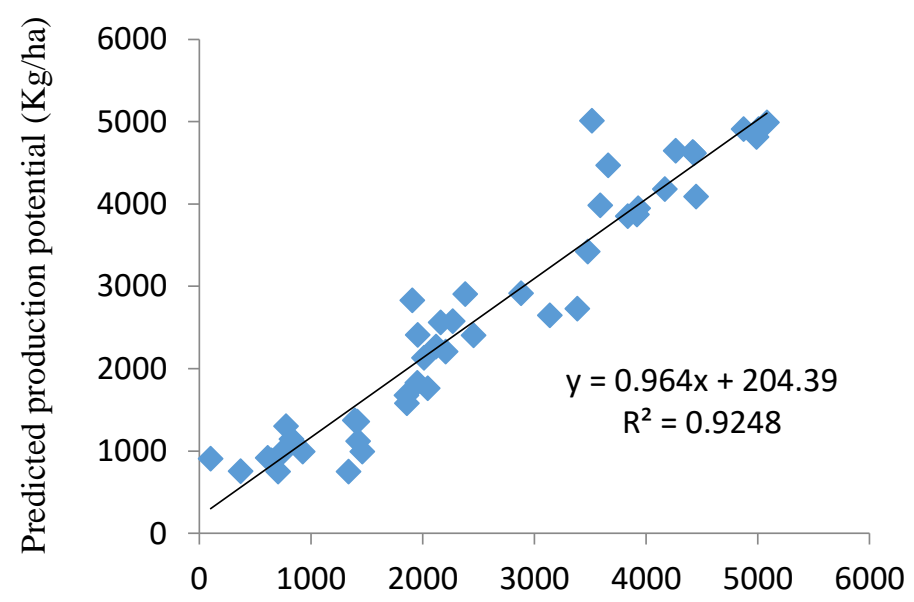

Actual production potential $(\mathrm{Kg} / \mathrm{ha})$

Figure 1. Relationship between actual and predicted production potential for wheat by neural network 
Table 6. Summary statistics of actual and predicted production potential by artificial neural networks

\begin{tabular}{lcccc}
\hline Crop & $\begin{array}{c}\text { Production potential } \\
\text { (kg/ha) }\end{array}$ & Minimum & Maximum & Mean \\
\hline \multirow{2}{*}{ Wheat } & $\begin{array}{c}\text { Actual production potential } \\
\text { Predicted production potential } \\
\text { by ANN }\end{array}$ & 101 & 5080 & 2503 \\
\hline \multirow{2}{*}{ Barley } & $\begin{array}{c}\text { Actual production potential } \\
\text { Predicted production potential } \\
\text { by ANN }\end{array}$ & 949 & 5013 & 2617 \\
\hline \multirow{2}{*}{ Maize } & $\begin{array}{c}\text { Actual production potential } \\
\text { Predicted production potential } \\
\text { by ANN }\end{array}$ & 124 & 4769 & 2350 \\
\hline
\end{tabular}

According to Table 7, SAR and clay percent, which have the coefficient of sensitivity: 6.12 and 5.96, respectively, were as the most effective factors for wheat production potential prediction. The reason for the yield decline due to salinity has been attributed to competition between sodium and chloride ions in nutrient uptake. In saline soil, the balance in nutrient uptake was disturbed (Hosseinifard et al., 2005). In coarse soil texture, high percentage of nitrogen was leached out of the root zone. Although in fine soil texture, nitrogen leaching is more limited than sandy soils, but more nitrogen volatilization was occurred (Salehi et al., 2009).So, mineral soil particles (sand, silt and clay) as the effective factors on soil fertility are very important in crop yield. The finding results of this research also confirm it.

Table 7. Sensitivity coefficients of used parameters in the neural network

\begin{tabular}{|c|c|c|c|c|c|c|}
\hline \multirow[b]{2}{*}{$\begin{array}{l}\text { Removed } \\
\text { factor }\end{array}$} & \multicolumn{2}{|c|}{ Wheat } & \multicolumn{2}{|c|}{ Barley } & \multicolumn{2}{|c|}{ Maize } \\
\hline & $\begin{array}{l}\text { Sensitivity } \\
\text { coefficient }\end{array}$ & RMSE & $\begin{array}{l}\text { Sensitivity } \\
\text { coefficient }\end{array}$ & RMSE & $\begin{array}{l}\text { Sensitivity } \\
\text { coefficient }\end{array}$ & RMSE \\
\hline- & -2 & 0.170 & - & 0.241 & - & 0.234 \\
\hline $\mathrm{EC}(\mathrm{dS} / \mathrm{m})$ & 4.92 & 0.836 & 1.54 & 0.371 & 6.65 & 1.556 \\
\hline $\mathrm{pH}$ & 2.15 & 0.366 & 2.85 & 0.687 & 1.98 & 0.463 \\
\hline SAR & 6.12 & 1.040 & 1.95 & 0.470 & 7.26 & 1.699 \\
\hline $\mathrm{CaCO}_{3}(\%)$ & 3.72 & 0.632 & 2.23 & 0.537 & 2.26 & 0.529 \\
\hline $\begin{array}{l}\text { Coarse } \\
\text { fragments (\%) }\end{array}$ & 3.55 & 0.604 & 4.86 & 1.171 & 2.75 & 0.644 \\
\hline Gypsum (\%) & 1.53 & 0.260 & 2.98 & 0.718 & 3.96 & 0.927 \\
\hline Clay (\%) & 5.96 & 1.013 & 3.5 & 0.844 & 4.25 & 0.995 \\
\hline Silt (\%) & 1.65 & 0.281 & 0.86 & 0.207 & 0.69 & 0.161 \\
\hline Sand $(\%)$ & 2.96 & 0.503 & 6.45 & 1.554 & 3.12 & 0.730 \\
\hline
\end{tabular}

\section{Barley production potential prediction by proposed ANN model}

Model No. 7 as the best ANN model (Table 5) for estimation of barley production potential, has 10 input layers and one output layer. The number of neurons in two hidden layers has been taken as 5 and 11. Fig. 2 shows the correlation between the calculated FAO production potential and the predicted ANN production potential for 
barley $\left(\mathrm{R}^{2}=0.866\right)$. This model estimated the highest and the lowest barley production potential of 4764 and $252(\mathrm{~kg} / \mathrm{ha})$, respectively (Table 6$)$. The results of coefficient of determination, RMSE and MAE, which are 0.892, 0.299 and 0.235, respectively; confirmed the effectiveness of proposed model (Table 4).

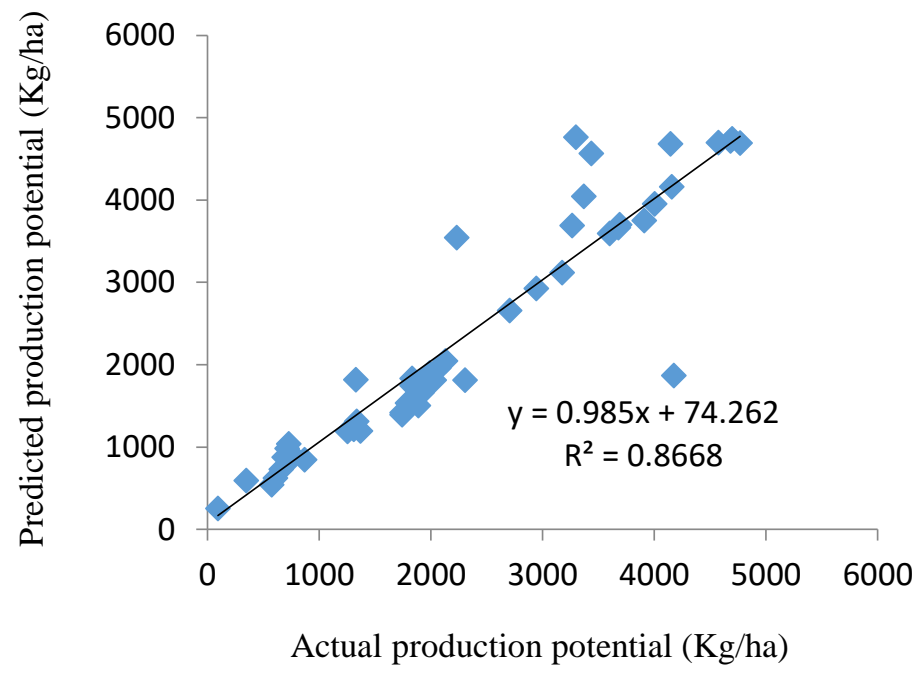

Figure 2. Relationship between actual and predicted production potential for barley by neural network

The results of sensitivity analysis indicate that the percentage of sand with the coefficient of sensitivity of 6.45 is the most important parameter for predicting of barley production and after that is the coarse fragment percent with the sensitivity coefficient of 4.86 (Table 7). Since, the studied soils with sand and coarse fragments of $75.3 \%$ and $23.6 \%$, respectively (Table 2) are gravelly soils, therefore these factors are the main constraint for barley production in the study area. The reason for this could be a direct or indirect impact of these factors on the supply and maintenance of required air, water and nutrients for plant. Ranjbar et al. (2015) have reported similar findings about the influence of some soil physical properties included percentage of coarse fragments, mineral soil particles (sand, silt and clay) and weighted mean diameter of aggregates on nutrient uptake. Also, according to the growing requirements of barley (Sys et al., 1993), coarse soil textures are unsuitable for barley production.

\section{Maize production potential prediction by proposed ANN model}

Model No. 5 with two hidden layers and a network structure of 9-6-8-1 (Table 3) shows the highest ranking in training process (Table 5). Fig. 3 shows high correlations between calculated FAO production potential and predicted ANN production potential for maize $\left(R^{2}=0.868\right)$. The highest and the lowest estimated maize production potential by optimum model were: 6083 and $667(\mathrm{~kg} / \mathrm{ha})$, respectively (Table 6). The results of coefficient of determination, RMSE and MAE, which are 0.746, 0.426 and 0.352 , respectively; confirmed the effectiveness of proposed Ann model (Table 4). According to Table 7, SAR and electrical conductivity, which have the coefficient of sensitivity: 7.26 and 6.25, respectively, were the most effective factors for maize production 
potential prediction. Available information about the growing requirements of maize (Sys et al., 1993) shows the more sensitivity of maize to soil salinity and sodium content than wheat and barley. The results of studies by Khaghani et al. (2012) showed that the toxicity of chloride and sodium ions compared to chloride and magnesium ions in equal osmotic pressure led to the more reduction of maize performance.

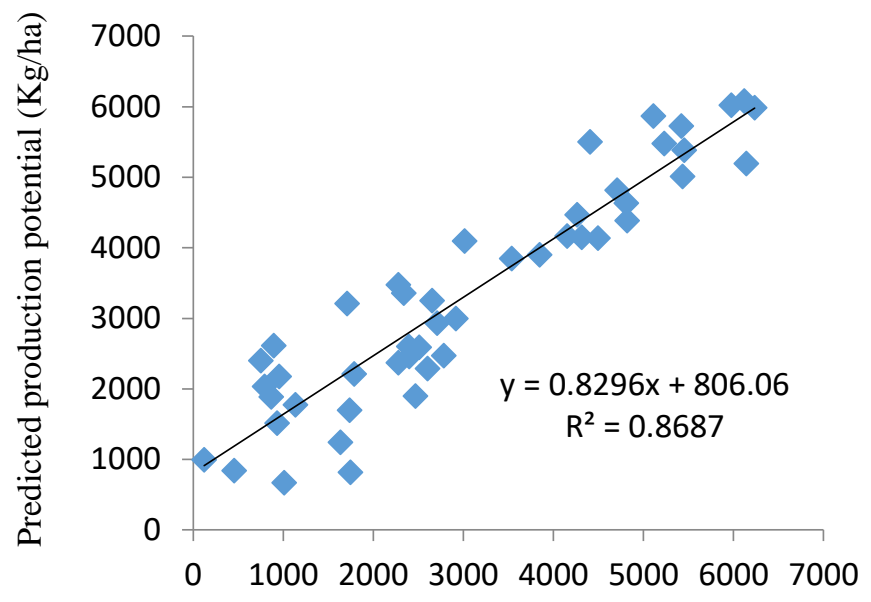

Actual production potential $(\mathrm{Kg} / \mathrm{ha})$

Figure 3. Relationship between actual and predicted production potential for maize by neural network

RMSE, MAE and $\mathrm{R}^{2}$ statistics of suggested models show that ANN models with two hidden layers have higher efficient than those with one hidden layer for production potential prediction of all three products (Tables 4 and 5). Safa et al. (2003), Kaul et al. (2005), Alvarez (2009) and Bagheri et al. (2012) showed that the efficiency of ANN model is increasing with the increment of hidden layer numbers. Although these models with two hidden layers were the most efficient model for estimation of wheat, barley and maize production potential, but the number of neurons in each hidden layer for each crop is different (Table 3). The reason of this can be the difference between climatic and soil requirements of each crop. Askari et al. (2009) investigated the efficiency of ANN for estimation of wheat, barley and maize yields. He found similar results in terms of the number of hidden layers and the number of neurons in the hidden layers of the optimum ANN models.

RMSE, MAE and $\mathrm{R}^{2}$ statistics in the testing process (Table 4) show the higher efficiency of model for barley predicts yield (model 7) than wheat (model 7) and maize (model 5) and also the higher efficiency of model for wheat yield prediction compared to maize. The reason of this may be differences in the environmental compatibility of various products to adverse conditions. So that, barley has higher environmental compatibility compared to wheat and maize. It is also true about wheat compared to maize. Drummond et al. (2003) mentioned the more capability of ANN for yield prediction of crops with more resistance and environmental comparability.

High correlations between calculated FAO production potential and predicted ANN production potential for studied crops demonstrated that that the reliability of ANN for 
production potential prediction is acceptable in this research. This proves the high accuracy of ANN method in accordance with the nonlinear performance of crops and the influence of many factors such as climate, soil and management on it. The ability of neural network method in describing the nonlinear relation of variables for yield prediction was reported by Zare Abyaneh (2012).

\section{Conclusions}

The ANN can predict the crop production potential by land characteristics in the study area. The ANN models with two hidden layers provided the most accurate prediction of crop yield. Also, the optimum model for maize production potential has less accuracy than wheat and barley. It may be due to differences in the environmental compatibility of various crops to adverse conditions. Therefore, it can be said that the higher environmental compatibility affects the efficiency level of ANN for production potential prediction. Generally, the results of this research show that ANN method has high capability to predict the land production potential. It can be attributed to the nonlinear relation of the production potential with effective variables and the ability of neural networks in nonlinear mapping. It should be noted that using climatic and plant parameters must be considered in neural networks modeling in areas with different agricultural, ecological zones.

\section{REFERENCES}

[1] Alvarez, A. (2009): Predicting average regional yield and production of wheat in the Argentine Pampas by an artificial neural network approach. - European Journal of Agronomy 30: 70-77.

[2] Askari, M. S., Khodadadi, M., Sarmadian, F., Gazni, R. (2009): Evaluation of artificial neural network techniques for estimating maze, wheat and barley yields. - Agronomy Journal 85:62-71. (In Persian)

[3] Bagheri, S., Gheysari, M., Ayoubi, Sh., Lavaee, N. (2012): Silage maize yield prediction using artificial neural networks. - Journal of Plant Production 19: 77-96. (In Persian).

[4] Bishop, C. M. (1995): Neural Networks for Pattern Recognition. - Oxford University Press, Oxford.

[5] Drummond, S. T., Sudduth, K. A., Joshi, A., Birrell, S. J., Kitchen, N. R. (2003): Statistical and neural methods for site-specific yield prediction. - Transactions of the ASAE 46(1): 5-14.

[6] Hosseinifard, J., Naghavi, H., Jalalian, A., Eghbal, M. (2005): Physicochemical and mineralogical properties of selected soils in the Rafsanjan pistachio area, Iran. - In IV International Symposium on Pistachio and Almond, ISHS, Tehran, Iran.

[7] Kaul, M., Hill, R. L., Walthall, C. (2005): Artificial neural networks for corn and soybean yield prediction. - Agricultural Systems 85: 1-18.

[8] Khaghani, R., Mahmoudi, Sh., Pazira, E., Masihabadi, M. H. (2012):Studying salinity and the effects on major crop yields in Qazvin plain. - Crop Production in Environmental Stress 4(3): 28-37. (In Persian).

[9] Kitchen, N. R., Drummond, S. T., Lund, E. D., Sudduth, K. A., Buchleiter, G. W. (2003): Soil electrical conductivity and topography related to yield for three contrasting soil-crop systems. - Agronomy Journal 95: 483-495.

[10] Montazar, A. A., Azadegan, B., Ahahraki, M. (2009): Assessing the efficiency of artificial network models to predict wheat yield and productivity based on climate data 
and seasonal water nitrogen variables. - Iranian Jouranl of Water Research 3: 17-27. (In Persian)

[11] Norouzi, M., Ayoubi, Sh., Jalalian, A., Khademi, H., Dehghani, A. A. (2010): Predicting rainfed wheat quality and quantity by artificial neural network using terrain and soil characteristics. - Acta Agriculturae Scandinavica 60: 341-352.

[12] Pachepsky, Y. A., Timlin, D., Varallyay, G. (1996): Artificial neural networks to estimate soil water retention from easily measurable data. - Soil Science Society of America Journal 60: 727-733.

[13] Qian, B., Jong, R. D., Warren, R., Chipanshi, A., Hill, H. (2009): Statistical spring wheat yield forecasting for the Canadian prairie provinces. - Agricultural and Forest Meteorology 149: 1022-1031.

[14] Ranjbar, A., Emami, H., Karimi-Karouyeh, A., Khorassani, R. (2015): Determining the most important soil properties affecting the yield of saffron in the Ghayenat area. Journal of Water and Soil 29(3): 673-682. (In Persian)

[15] Safa, B., Khalili, A., Tashnehlab, M., Liaghat, A. (2003): Predicting wheat yield using Artificial Neural Network. - Journal of Nivar 12: 47-62.

[16] Safa, B., Samarasinghe, S., Nejat, M. (2015): Prediction of Wheat Production Using Artificial Neural Networks and Investigating Indirect Factors Affecting It: Case Study in Canterbury Province, New Zealand. - Journal of Agricultural Science and Technology 17: 791-803.

[17] Salehi, M. H., Heydari, M., Mohamadkhani, A. R., Hosseinifard, J. (2009): The effect of some soil properties on pistachio yield in the Anar of Rafsanjan area. - Soil Research 23(1): 35-47. (In Persian).

[18] Shearer, S. A., Burks, T. F., Fulton, J. P., Higgins, S. F. (2000): Yield prediction using a neural network classifier trained using soil landscape features and soil fertility data. - In: Proceeding of Annual International Meeting, Midwest Express Center, Milwaukee, Wisconsin.

[19] Soil Survey Staff. (1996): Soil Survey Laboratory Methods Manual: Soil Survey Investigations Report No. 42. - USDA, NRCS, NCSS, USA.

[20] Soil Survey Staff. (2014): Keys to Soil Taxonomy (p. 358) (12th ed.). - USDA-Natural Resources Conservation Service, Washington D.C.

[21] StatSoft Inc. (2004): Electronic Statistics Textbook [Online]. - Available at http://www.statsoft.com/ textbook/stathome.html.

[22] Sys, C., Van Rans, E., Debaveye, J. (1991): Land Evaluation. Part II: Methods in Land evaluation.Administration for Development Cooperation. - Agricultural Publication No. 7., Brussels, Belgium.

[23] Sys, C., Van Rans, E., Debaveye, J., Beernaert, F. (1993): Land Evaluation. Part III: Crop Requirements. General Administration for Development Cooperation. - Agricultural Publication No. 7., Brussels, Belgium.

[24] Tang, H., Van Ranst, E., Groenemans, R. (1997): Application of fuzzy set theory to land suitability assessment. - Trends in Soil Science 2: 191-203.

[25] Wieland, V., Mirschel, V. (2008): Adaptive fuzzy modeling versus artificial neural network. - Environmental Modelling \& Software 23: 215-224.

[26] Zare Abyaneh, H. (2012): Evaluation of artificial neural network and geostatistical methods in estimating the spatial distribution of irrigated and dry wheat yield (Case Study: Khorasan Razavi). - Physical Geography Research Quarterly 4: 23-42. (In Persian)

[27] Zhang, W. J., Bai, C. J., Liu, G. D. (2007): Neural network modeling of ecosystems: A case study on cabbage growth system. - Ecological Modelling 201: 317-325. 